\title{
REVISÃO: TECNOLOGIAS NÃO CONVENCIONAIS E O IMPACTO NO COMPORTAMENTO DO CONSUMIDOR
}

\author{
MARIA CRISTINA DA COSTA * \\ ROSIRES DELIZA \\ AMAURI ROSENTHAL **
}

\begin{abstract}
Apresenta revisão de literatura sobre tecnologias não convencionais para a obtenção de produtos alimentícios, enfatizando as características individuais dos consumidores, que afetam diferentemente a percepção do produto.
\end{abstract}

\section{INTRODUÇÃO}

A crescente demanda do mercado consumidor por produtos de alta qualidade revela a necessidade da utilização de tecnologias, que propiciem seguridade microbiológica na produção, aumentando sua vida útil, e que ainda proporcionem mínimas alterações na qualidade nutricional e sensorial dos alimentos. Tais tecnologias, diferentemente dos processos tradicionais, visam diminuir as perdas de componentes termossensíveis, responsáveis por estas qualidades sensoriais e nutricionais (LEISTNER \& GORRIS, 1995; HOOVER, 1997; VEGA-MERCADO, 1997). Além de preservar as características do alimento, as novas tendências em tecnologia devem buscar também seguridade para o meio ambiente, revelando preocupação com o equilíbrio entre a produção e o consumo de alimentos. Uma das conseqüências desta demanda é o crescente interesse por tecnologias de processamento/conservação que não provoquem alterações indesejáveis no alimento e também não agridam o meio ambiente, sendo denominadas de "tecnologias não convencionais", "tecnologias emergentes", "tecnologias limpas" ou "tecnologias de baixo impacto ambiental". Conseqüentemente, a partir destas novas tecnologias surgiram novos produtos, e o julgamento e a aceitação destes pelo consumidor determinará seu sucesso ou fracasso comercial, representando, deste modo, a avaliação da tecnologia utilizada e do produto final obtido (ZIMMERMAN et al. 1994; FREWER et al., 1995; HOBAN, 1996a).

\footnotetext{
Mestranda em Ciência e Tecnologia de Alimentos, Universidade Federal Rural do Rio de Janeiro.

* Pesquisadores da EMBRAPA, Agroindústria de Alimentos, Rio de Janeiro - RJ - Brasil.
} 
Algumas pesquisas (HASHIM et al., 1996; FREWER et al., 1996b; FREWER et al., 1998) têm se baseado nas respostas dos consumidores com o objetivo de estudar a aceitabilidade de determinados produtos, exatamente porque, a percepção de qualidade, seguridade, confiabilidade, e consciência em relação à tecnologia que foi utilizada para a obtenção daquele determinado produto, assim como suas vantagens e desvantagens, associadas aos possíveis riscos, certamente se refletirão na intenção de compra e posterior consumo.

\section{NOVAS TENDÊNCIAS EM TECNOLOGIA DE ALIMENTOS}

Os processos não térmicos vêm ganhando notória importância como tecnologia eficiente para substituir ou complementar os tratamentos térmicos tradicionais. Comparados com os processos térmicos, os processos não térmicos oferecem as vantagens de baixa temperatura de processamento, baixa utilização de energia e a retenção de nutrientes e de sabor semelhante ao produto fresco, enquanto elimina esporos de microorganismos e inativa enzimas (VEGA-MERCADO et al., 1997).

Dentre as tendências em tecnologia de alimentos, com as características relacionadas anteriormente, pode-se destacar o processamento mínimo de alimentos, também conhecidos como "alimentos minimamente processados" ou "fresh-cut", os métodos combinados de conservação de alimentos, baseados na "teoria dos obstáculos", a alta-pressão, os pulsos elétricos (pef), o aquecimento ôhmico, a irradiação, a engenharia genética e a biotecnologia, entre outros.

\subsection{BIOTECNOLOGIA E ENGENHARIA GENÉTICA}

A biotecnologia pode ser definida, de maneira bem ampla, como a utilização integrada da bioquímica, microbiologia, engenharia genética e engenharia de processos, incluindo áreas tecnológicas como: DNArecombinante, que é a inserção de DNA em sistema diferente do original; tecnologias de enzimas; cultura de células; fusão de duas células, gerando híbridos; engenharia de processos e a tecnologia de fermentação. Deste modo, tal tecnologia pode ser aplicada para a obtenção de produtos alimentícios e de matéria-prima (MITTAL, 1992).

Os processos de fermentação com microorganismos para melhorar o sabor, os alimentos fermentados (pães, cerveja, vinho, iogurte, queijo, molhos de soja), as culturas de células e a modulação de processos metabólicos pós-colheita para prolongar a vida de prateleira de frutas e vegetais frescos são alguns exemplos do uso da biotecnologia na área de alimentos. Outros exemplos são os processos com enzimas purificadas para melhorar a qualidade dos alimentos, o bioprocessamento como o uso 
de membranas e a reprodução e embriologia em animais (SHEWRY \& LAZZERI, 1996; BULFIELD, 1996; TUCKER, 1996).

A engenharia genética baseia-se na cópia de um gen que se deseja em particular, o qual é inserido dentro do DNA, ou emendado ao DNA de outra planta, microorganismo ou animal, resultando na produção de "novos" organismos. Estas mudanças podem gerar benefícios como qualidade melhorada, maior resistência a peste e doenças, variedades com maior rendimento, níveis de nutrientes aumentados ou diminuídos, melhor sabor e textura (ELLAHI, 1994; RUSSELL, 1998). O primeiro passo é a identificação do gen que carreia a característica que se deseja. O DNA que contém o gen de interesse é extraído do organismo original (animal, vegetal ou microorganismo). Este DNA é cortado em fragmentos menores, utilizando-se enzimas de restrição, que funcionam como "tesouras moleculares". Estes fragmentos são então ligados a outros fragmentos de DNA que podem ser replicados em bactérias. A partir deste ponto, a colônia de bactérias que contém o fragmento de DNA correspondente ao gen de interesse é selecionada, podendo-se então realizar a inserção no organismo que se deseja modificar (MITTAL, 1992).

Sendo tendência tecnológica bastante atual, a engenharia genética também é conhecida como "nova ou moderna biotecnologia". Uma das maiores vantagens da utilização da engenharia genética, principalmente para a agricultura e para o meio ambiente, é a possibilidade de obtenção de cultivares resistentes aos insetos e doenças, e conseqüentemente a redução do uso de pesticidas, resultando na produção de alimentos sem resíduos químicos e reduzindo inclusive os danos ambientais (PEACOCK, 1994; ELLAHI, 1994). Entretanto, segundo alguns autores (SCHER, 1993; VERRALL, 1994; GENETIC..., 1997). Pode-se considerar como possíveis perigos ou pontos negativos decorrentes do uso da engenharia genética o rompimento da cadeia alimentar, a criação de super ervas daninhas mais resistentes, o aumento da monocultura na agricultura e a possível transferência de gens responsáveis pela presença de substâncias alergênicas no alimento.

O uso da engenharia genética tem gerado bastante polêmica não só no meio acadêmico, mas também entre os grupos ativistas e os consumidores, tornando necessária a realização de pesquisas no sentido de se obter informações mais seguras sobre o uso desta tecnologia e aceitação dos produtos no mercado consumidor.

O crescente interesse por tecnologias alternativas que promovam o mínimo dano ao meio ambiente e à qualidade de vida futura, tem sido observado em conseqüência da grande preocupação com a preservação ambiental. 


\subsection{TECNOLOGIA DE ALTA-PRESSÃO}

A potencialidade do uso da alta-pressão como método para processar e conservar alimentos já era conhecida e estudada desde 1899 por HITE, mas ficou praticamente adormecida até a década de 80 , quando estudos a este respeito foram intensificados (HOOVER et al., 1989; MERTENS, 1992; KNORR, 1993; ARROYO \& PRESTAMO, 1996; EARNSHAW, 1996).

A tecnologia de alta-pressão consiste na aplicação de pressões hidrostáticas extremamente elevadas, na faixa de 100 a $1000 \mathrm{MPa}$, nos alimentos com o objetivo de alcançar máxima destruição de microorganismos e de enzimas indesejáveis, em temperatura ambiente. 0 princípio de destruição e/ou inativação de microorganismos deteriorantes baseia-se no rompimento de membranas e organelas celulares e desnaturação de proteínas componentes das membranas lipoprotéicas, bem como das enzimas microbianas. A desnaturação protéica é também responsável pela inativação de enzimas deteriorantes originárias do próprio alimento (CHEFTEL, 1995; EARNSHAW, 1996; ROSENTHAL \& SILVA, 1997; ROSENTHAL et al., 1999).

Para compreender os efeitos da alta pressão sobre os componentes alimentares é necessário conhecer seus princípios básicos como o princípio isostático, ou seja, a pressão é transmitida de maneira uniforme e instantânea por todo o alimento, independente da sua forma ou tamanho. O princípio de "Le Chatelier", de acordo com o qual todo e qualquer fenômeno (transição de fase, mudança na configuração molecular, reação química) acompanhado de decréscimo de volume é incrementado pela alta-pressão e, se acompanhado de aumento de volume é dificultado pela alta-pressão (CHEFTEL, 1995). Desta forma, uma das principais vantagens da utilização da alta-pressão para processar alimentos é o não rompimento das ligações químicas covalentes, as quais apresentam pequena compressibilidade, devido à mínima distância entre os átomos envolvidos na ligação (CHEFTEL, 1995). Este fato resulta na preservação dos principais compostos responsáveis pelo aroma, sabor e valor nutritivo, conservando a qualidade sensorial e nutricional dos alimentos.

O efeito letal da alta-pressão sobre as células vegetativas de microorganismos é provocado pela precipitação de proteínas, mas no caso dos esporos, as proteínas estão protegidas pelo "ácido dipicolínico", o que impede sua solvatação, excessiva ionização e conseqüente precipitação. Por esta razão, a aplicação somente de alta-pressão não é suficiente para inativá-los (SANGRONIS et al, 1997). Assim, a inativação de esporos requer germinação prévia, que é obtida mediante aplicação de níveis de pressão menores do que os utilizados no próprio processamento. Posteriormente, o alimento é submetido a elevados níveis de pressão, com subseqüente inativação das células vegetativas, oriundas dos esporos germinados, o que garante a seguridade microbiológica do produto. Pode- 
se optar ainda pela combinação de ciclos de pressão e temperaturas moderadas $\left(60^{\circ}\right.$ a $\left.90^{\circ} \mathrm{C}\right)$ no processo (CHEFTEL, 1995; ROSENTHAL \& SILVA, 1997). O estabelecimento da intensidade de pressão adequada para a inativação de enzimas nos alimentos é um ponto crítico na otimização do processo pois, dependendo do nível de pressão aplicado ao produto, as enzimas sofrem inativação ou são ainda mais ativadas pelo processo (HOOVER et al., 1989; ROSENTHAL \& SILVA, 1997).

Com relação ao meio de imersão, algumas concentrações de substâncias servem de proteção para a enzima dificultando a sua inativação, o que se denomina "efeito baroprotetor", como por exemplo, a concentração elevada de açúcar (SEYDERHELM et al, 1996). Em microorganismos, a composição do meio também pode influenciar os efeitos da alta-pressão. As soluções salinas sem nutrientes tendem a diminuir a tolerância dos microorganismos à pressão, enquanto que meio enriquecido com aminoácidos e vitaminas exerce "efeito baroprotetor" às células, dificultando a sua eliminação (HOOVER et al., 1989).

A tecnologia de alta-pressão apresenta reconhecido potencial de aplicação, não só com o objetivo de conservação, mas também para modificar a funcionalidade e melhorar as propriedades reológicas e sensoriais dos alimentos. A sua maior vantagem consiste na possibilidade de inativar microorganismos e enzimas com máxima retenção de vitaminas e de compostos responsáveis pelo sabor, cor e aroma, originando alimento de melhor qualidade (SANGRONIS et al., 1997).

\subsection{AQUECIMENTO ÔHMICO}

Na busca de novos e melhores métodos de conservação de alimentos, as pesquisas têm se voltado para a possibilidade de utilização de radiações de diferentes freqüências, que vão desde a corrente elétrica de baixa freqüência até os raios gama de alta freqüência.

A utilização da energia ôhmica para processar alimentos data de 1917, sendo entretanto ainda muito incipiente (LARKIN \& SPINAK, 1996). O princípio básico do aquecimento ôhmico é a passagem de corrente elétrica alternada de baixa freqüência $(50 \mathrm{a} 60 \mathrm{~Hz})$ através do alimento, gerando calor devido à resistência elétrica do mesmo (SKUDDER, 1989 citado por ZOLTAI \& SWEARINGEN, 1996; BHAT \& JOSHI, 1998).

O aquecimento ôhmico tem aplicação potencial em produtos que contém partículas, produzindo alimentos de mais alta qualidade, devido ao rápido e uniforme aquecimento do produto, sem ocasionar danos mecânicos às partículas, superaquecimento da parte líquida e perdas no valor nutricional e sensorial. Tais características diferenciam este método das técnicas convencionais de transferência de calor, as quais normalmente ocasionam 
sobre-processamento da parte líquida, o que pode acarretar perdas indesejáveis da qualidade do alimento (PARROT, 1992; WILLIAMS, 1993).

A eliminação de microorganismos pode ser realizada por três mecanismos, ou seja, efeitos mecânicos nas membranas celulares, efeitos químicos, e efeitos térmicos (BHAT \& JOSHI, 1998). Segundo KIM et al. (1996) muitos estudos ainda serão necessários para melhor elucidar os mecanismos de eliminação de microorganismos em alimentos com a utilização desta tecnologia. Entretanto, deve-se buscar ainda a otimização em relação ao tamanho, forma, concentração, densidade, condutividade e calor específico dos componentes do produto, que obviamente afetam o aquecimento do alimento. Deste modo, a viabilidade de aplicação comercial desta tecnologia depende de mais pesquisas na sua padronização (ZOLTAI \& SWEARINGEN, 1996; BHAT \& JOSHI, 1998).

\subsection{ALIMENTOS MINIMAMENTE PROCESSADOS}

Compreende-se por minimamente processados aqueles alimentos frescos, convenientemente descascados, sem caroços, fatiados e totalmente comestíveis. O mínimo processo inclui também os cuidados com o manuseio e estocagem pós-colheita, resfriamento e a utilização de embalagens adequadas para estes produtos (KLEIN, 1987; BOLIN \& HUXSOLL, 1989). Uma das maiores limitações da comercialização de alimentos minimamente processados é a vida útil relativamente reduzida, em conseqüência de alguns fatores como: o escurecimento enzimático, deterioração microbiana, descoloração de superfície, devido à formação de suberina e desidratação seguida pelo descascamento por abrasão; além da senescência ocasionada pela respiração do vegetal e a produção de etileno (REYES, 1996).

As operações envolvidas no preparo de frutos e vegetais minimamente processados (ou "fresh-cut") aumentam as taxas de deterioração. Os prejuízos físicos ou a injúria ocasionada pelo processo elevam a taxa respiratória e a produção de etileno em poucos minutos. Este aumento no metabolismo da fruta ou vegetal ocorre com aumentos associados nas taxas de outras reações bioquímicas responsáveis pelas mudanças na cor (incluindo o escurecimento enzimático), sabor, textura e qualidade nutricional (CANTWELL, 1995). As possíveis perdas nutricionais estão relacionadas principalmente com as vitaminas $A, C$ e folacina, entretanto KLEIN (1987) sugere que a busca de condições ótimas no processamento para a preservação das características sensoriais também mantém o valor nutricional do produto. Com isso, para aumentar a vida útil destes alimentos têm sido utilizadas embalagens com atmosfera modificada ("Modified Atmosphere Packaging" - MAP) associadas à temperatura reduzida, que em conjunto reduzem o metabolismo, sendo então responsáveis pela manutenção das características de frescor, maior tempo 
de vida útil, além de manter a sanitização do produto (CHRISTIE et al., 1995). A MAP consiste em adequar as proporções de gases dentro da embalagem aos diferentes produtos e seus estádios de maturação, utilizando normalmente filmes de permeabilidade conhecida para que se adquira equilíbrio nas concentrações destes gases. A escolha das concentrações iniciais de gases é influenciada pela flora microbiana potencialmente contaminante, sensibilidade ao $\mathrm{CO}_{2}$ e ao $\mathrm{O}_{2}$ e para os requerimentos de estabilidade da coloração no produto (PHILLIPS, 1996).

\subsection{IRRADIAÇÃO}

A irradiação de alimentos é uma tecnologia segura, definida como sendo o processo pelo qual o alimento é exposto à radiações ionizantes, em ambiente especial, por tempo específico e em condições controladas. A energia é suficiente para romper ligações químicas, provocando alterações não só nos componentes dos alimentos como também nos elementos contaminantes (HENSON, 1995; SENDRA et al., 1996). As radiações ionizantes permitidas para uso em alimentos podem ser de fontes mecânicas, como os equipamentos de raio $X$ que emitem energia eletromagnética e os equipamentos aceleradores de elétrons, que emitem radiações corpusculares $\beta$; e de substâncias radioativas, que consistem de fontes emissoras espontâneas de radiações gama, como o Cobalto 60 e o Césio 137 (SENDRA et al., 1996). A dose máxima de irradiação recomendada pela FAO/OMS no Codex Alimentarius é de 10 kGy (1995). A irradiação de alimentos com fontes permitidas e em doses recomendadas não resulta em radioatividade induzida nos produtos, nem representa risco para a saúde humana.

O processo de irradiação é limitado pelas possíveis alterações nos componentes dos alimentos, como a formação de radicais instáveis, desnaturação de proteínas dependendo da dose de radiação utilizada, mudanças oxidativas em lipídios e degradação de vitaminas. Esta última, entretanto, é comparável àquela degradação que ocorre com tecnologia convencional. A irradiação pode desenvolver sabor estranho em alimentos, alterando, assim, suas qualidades sensoriais (THAKUR \& SINGH, 1994). Para minimizar estas possíveis alterações causadas pela irradiação devese observar as condições do processo, evitando a presença de oxigênio, utilizando baixas temperaturas, controlando $\mathrm{o} \mathrm{pH}$ e utilizando fontes e doses de radiação permitidas (THAKUR \& SINGH, 1994; SENDRA et al., 1996).

A irradiação apresenta potencial de aplicação em alimentos, e tem sido utilizada para descontaminação de grãos e farinhas, no controle de amadurecimento de frutas e vegetais, retardando a senescência e diminuindo as perdas pós-colheita. Pode também ser utilizada na inibição de germinação em bulbos e tubérculos, no controle de deterioração de 
alimentos de origem animal, no tratamento alternativo ao uso de aditivos, além de apresentar seguridade microbiológica para os alimentos, evitando doenças causadas por microorganismos de importância em saúde pública (THAKUR \& SINGH, 1994; SENDRA et al., 1996; PSZCZOLA, 1997).

A aplicação comercial da irradiação depende principalmente da aceitação dos consumidores e a indústria hesita em adotar tal tecnologia preocupada com a opinião do público alvo. Pesquisas têm sido realizadas (POLHMAN et al., 1994; HENSON, 1995; HASHIM et al., 1996) com o objetivo de estudar o nível de conhecimento e aceitabilidade dos produtos irradiados, assim como a influência da informação sobre esta tecnologia na aceitabilidade dos produtos. Estudo realizado por SCHUTZ \& CARDELLO (1997) com população de militares americanos revelou baixo nível de consciência, mas alto nível de interesse por alimentos irradiados. A mesma pesquisa mostrou que, a utilização de vídeo informativo sobre o processo de irradiação de alimentos, dentre outros métodos para veicular informação confiável sobre segurança e uso de alimentos irradiados, pode aumentar a aceitabilidade e a probabilidade de consumo destes produtos.

\subsection{PULSOS ELÉTRICOS (PEF)}

A utilização de pulsos elétricos de curta duração ("Pulsed Electric Fields PEF"), como alternativa à tecnologia convencional, tem aumentado devido ao seu potencial emprego na esterilização/pasteurização de alimentos (CASTRO et al., 1993; QIN et al., 1995).

A câmara utilizada para o tratamento do alimento consiste em dois eletrodos entre os quais o produto passa e os pulsos de alta intensidade e de curta duração ( $\mu \mathrm{s})$ são aplicados com energia entre 20 a $80 \mathrm{KV} / \mathrm{cm}$. O tempo de permanência do produto dentro da câmara, o número de repetições ou freqüência dos pulsos, e a duração e intensidade determinam o nível do tratamento (DUNN, 1996). A destruição de microorganismos ocorre sob campo elétrico externo de curta duração ( $\mu \mathrm{s})$ e é causada por mudanças estruturais irreversíveis, como a formação de poros e, conseqüentemente a destruição da barreira semipermeável da membrana celular (CASTRO et al., 1993; DUNN, 1996; MARQUEZ et al., 1997). Esta tecnologia parece ter futuro promissor, visto que origina produtos estáveis e de qualidade melhorada, por assegurar maior retenção de sabor, aroma, cor, valor nutricional, melhor funcionalidade das proteínas, eliminação dos danos às emulsões, aumento da vida de prateleira, melhor controle das fermentações (DUNN, 1996) e eliminação dos resistentes esporos bacterianos (MARQUEZ et al., 1997).

A aplicação potencial na indústria alimentícia se destaca para alimentos líquidos, principalmente leite, iogurtes, sucos de frutas, ovos líquidos e sopas (QIN et al., 1995; ZHANG et al., 1995; VEGA-MERCADO, 1997). 


\subsection{MÉTODOS COMBINADOS PARA CONSERVAR ALIMENTOS}

A utilização desta tecnologia data de milênios, sendo encontradas referências na Bíblia e nos antigos registros históricos, mas o primeiro passo para o seu avanço foi a utilização em produtos para animais domésticos, como relatam TORREZAN et al., 1997.

A preservação de alimentos pelo uso de métodos combinados consiste na aplicação de vários parâmetros, também chamados de obstáculos, que possam agir sinergisticamente para inibir ou retardar o crescimento microbiano, resultando em produtos estáveis a temperatura ambiente (CHIRIFE \& FAVETTO, 1992). Estes métodos baseiam-se na utilização de processos brandos, e LEISTNER \& GORRIS (1995) revelaram ampla variedade de obstáculos utilizáveis, entre os quais: alta e baixa temperatura, radiação, energia eletromagnética, ultrassom, baixa atividade de água, baixo pH, baixo potencial redox (Eh), sais, gases (dióxido de carbono, oxigênio, ozônio), ácidos orgânicos, sulfitos, defumação, produtos da reação de Maillard, condimentos e especiarias, enzimas e flora competitiva. Além disso, obstáculos emergentes como alta-pressão, embalagens com atmosfera modificada, bacteriocinas e embalagens de filmes comestíveis, também podem ser utilizados. Estes fatores, separada e/ou conjuntamente, funcionam como barreiras para impedir que os microorganismos encontrem condições favoráveis ao seu desenvolvimento e/ou à produção de toxinas. Deste modo, combinando-se intensidade e tipo de obstáculo com o produto adequado pode-se promover a estabilidade microbiológica necessária para a segura comercialização.

Tradicionalmente, com a aplicação de métodos combinados pode-se obter dois tipos de produtos: os alimentos auto estáveis (AAE) e os alimentos de umidade intermediária (AUI). Os alimentos de umidade intermediária (AUI) são aqueles conservados com o ajuste adequado de formulação em termos de composição, $\mathrm{pH}$, aditivos, etc. e mantendo a atividade de água entre 0,60 e 0,84 a $25{ }^{\circ} \mathrm{C}$. Entretanto, existem na literatura variações nas faixas de atividade de água, discutidas por ERICKSON (1982), que geralmente ficam entre 0,60 e 0,90, e seu conteúdo de água entre 10 e $40 \%$. Os alimentos auto estáveis (AAE) são basicamente aqueles com umidade intermediária, porém com atividade de água pouco mais elevada (TORREZAN, 1997).

Os métodos combinados asseguram estabilidade e segurança apesar da utilização de tratamentos brandos e resulta em produtos com boa qualidade sensorial e nutricional (LEISTNER, 1992). Entretanto, sua aplicação ainda esbarra na incompatibilidade entre o sabor dos alimentos e dos depressores de atividade de água (doçura da sacarose, o sabor salgado dos sais e o sabor metálico do glicerol), revelando a necessidade de maiores cuidados na escolha do soluto e na determinação das quantidades utilizadas (TAOUKIS et al., 1988). O desafio está exatamente 
em pesquisar solutos que diminuam a atividade de água sem afetar consideravelmente as características sensoriais dos alimentos (CALVIDAL, 1981). Sua aplicabilidade pode ser ressaltada principalmente para o armazenamento de frutas e hortaliças a granel, garantindo o consumo na entressafra, épocas nas quais normalmente estes produtos não estariam disponíveis (JARDIM, 1996).

\section{IMPACTO DE NOVAS TECNOLOGIAS SOBRE O CONSUMIDOR}

As indústrias de alimentos estão mudando, gradativamente, na tentativa de atender às expectativas do consumidor (McLLVEEN, 1994). A pressão exercida pelo aumento de competição global, o desenvolvimento de novas tecnologias, as mudanças demográficas, econômicas e políticas, bem como o possível impacto ambiental, geram nova visão de mercado, cada vez mais exigente. Historicamente, a ciência e a tecnologia faziam parte da lógica inquestionável que envolvia crescimento econômico e progresso. Mais recentemente, a consciência de efeitos negativos do uso da tecnologia convencional, como por exemplo, problemas ambientais em larga escala, alergias aos aditivos, resíduos de pesticidas e hormônios deixados nos alimentos, têm aumentado e se tornado mais um item em discussão (HAMSTRA et al., 1996).

O interesse da sociedade por questões relacionadas à proteção ambiental reflete-se cada vez mais no comportamento dos indivíduos (WATTS et al, 1990; ROTH, 1990; CHAN, 1996). Hoje, o consumidor está muito mais preocupado com a qualidade do alimento, considerando não somente suas características sensoriais, mas também sua seguridade microbiológica, seu valor nutricional relacionado com seu estado de saúde, além da possível contaminação por resíduos químicos na produção e poluição do meio ambiente.

WATTS et al. (1990) revelaram que consumidores canadenses estão atentos para as questões ambientais, evidenciando a necessidade da indústria alimentícia em se empenhar ainda mais no aumento da produção de alimentos, utilizando tecnologia de baixo impacto ambiental. Tal fato, motivou o desenvolvimento das tecnologias emergentes (aquecimento ôhmico, alta-pressão, métodos combinados e biotecnologia) que são potencialmente de baixo impacto ambiental. $O$ interesse pela preservação do meio ambiente, não lançando resíduos tóxicos no ar, na água e/ou no próprio alimento, além de contribuir para a diminuição dos gastos energéticos é considerado como principal ponto em comum entre tais tecnologias.

Em geral, as tecnologias relacionadas à produção de alimentos são vistas como de "alto risco e baixo benefício", possivelmente devido à preferência do consumidor por produtos "naturais". Deste modo, a ênfase nos 
benefícios de determinada tecnologia pode facilitar a aceitação pública de novos produtos (FREWER et al., 1995). Segundo HOBAN (1996a) os possíveis riscos associados às tecnologias são percebidos como mais sérios quando considerados "artificiais", reforçando a idéia de que "o natural é mais seguro".

Muitas pesquisas (SCHOLTEN et al., 1991; ZIMMERMAN et al., 1994; FREWER et al., 1995; HAMSTRA et al., 1996; HOBAN, 1996b; HOBAN, 1996c; AHSON, 1997) têm sido realizadas objetivando confirmar a correlação existente entre a aceitabilidade de determinados produtos e tecnologias emergentes, e a percepção dos benefícios para o próprio consumidor, para a sua saúde, meio ambiente e/ou para o bem-estar dos animais. Além disso, considerações éticas, crenças e tabus sobre determinados processos utilizados na produção de alimentos, também interferem na avaliação do produto. Por exemplo, o uso da biotecnologia é mais aceito, de maneira decrescente, em plantas, em microrganismos, em animais e em seres humanos.

A aceitação pública da biotecnologia só é alcançada quando se produz alimentos seguros, sem deixar suspeitas sobre riscos para a saúde e para o meio ambiente (FEEHAN, 1997). Por isso, a preocupação com a segurança da vida humana e do meio ambiente deve ser constante nos programas de educação e conscientização dos consumidores.

WANDEL \& BUGGE (1997) revelaram que, 35\% dos consumidores consideram o aspecto ambiental na comparação com outros atributos de qualidade e estavam dispostos a adquirir os produtos obtidos por tecnologias de baixo impacto ambiental, mesmo se o preço fosse mais elevado. YEE (1997) verificou que 54\% dos consumidores de Hong-Kong estavam dispostos a mudar a compra de alguns produtos por razões ecológicas, e destes $41 \%$ pagariam até $20 \%$ a mais por produtos obtidos por tecnologias de baixo impacto ambiental.

Dentre as tecnologias não convencionais, as maiores polêmicas giram em torno da irradiação e da engenharia genética, devido à falta de conhecimento sobre suas potencialidades. Estudos mostraram que na medida em que cresce o conhecimento sobre benefícios destas tecnologias e possíveis riscos, a aceitabilidade dos produtos é aumentada (ZIMMERMAN et al., 1994; POHLMAN et al., 1994; HASHIM et al., 1996; FREWER et al., 1998). FREWER (1996b) estudou a aceitabilidade de alimentos obtidos com o uso de engenharia genética, pesquisando a influência da informação na atitude em relação à tal tecnologia. Concluiu que o fator que mais influenciou a aceitação da engenharia genética foi a percepção dos benefícios, como melhor valor nutricional, vida de prateleira aumentada, melhor preço, além de benefícios para o meio ambiente. A importância relativa da utilização de engenharia genética, na obtenção de queijo e os benefícios dela decorrente, foi investigada por FREWER et al. 
(1996b) e relacionada com a intenção de compra destes produtos. Os consumidores recebiam informação sobre as diferentes tecnologias utilizadas, sendo informado a um grupo apenas os benefícios gerais e a outro os benefícios específicos. Constatou-se que o fator mais importante na decisão de compra do produto foi a percepção de benefício direto que a tecnologia oferecia para o próprio consumidor, como por exemplo, melhora do valor nutricional e preço reduzido. Os benefícios relacionados ao meio ambiente e ao bem-estar dos animais também foram considerados relevantes. Em estudo comparativo entre países, FREWER et al. (1998) correlacionaram o uso de biotecnologia e a atitude do consumidor, mostrando que houve preocupação maior entre os italianos em relação às questões éticas, e entre os ingleses quanto aos possíveis riscos associados ao uso da tecnologia. A percepção dos benefícios pelos consumidores foi aspecto relevante na aceitação da engenharia genética em ambos os países.

Para muitos consumidores a aceitação de produtos desenvolvidos pela biotecnologia passa pelo domínio afetivo, mais do que pelo domínio cognitivo, sendo influenciada por questões éticas e morais (JONES, 1996; ZIMERMMAN et al. 1994), além de características psicológicas que determinam percepções diferenciadas de riscos, estabelecendo reações e comportamentos que variam de indivíduo para indivíduo (FREWER et al., 1995).

A maioria dos consumidores precisa de algum tipo de informação sobre os produtos obtidos por novas tecnologias, entretanto as questões relacionadas à aceitação de tais tecnologias, não podem ser resolvidas apenas com campanhas de informação pública isoladamente (HAMSTRA et al, 1996). Em busca de soluções, um dos caminhos seria melhorar a rotulagem objetivando alcançar a expectativa do consumidor, associando outras fontes de informação confiáveis que atinjam grande faixa da população consumidora. Assim, torna-se necessária maior ênfase na identificação dos tipos de mensagens que teriam maior impacto na promoção de atitudes positivas em torno dos produtos envolvendo novas tecnologias. Segundo HOBAN (1996b) os consumidores precisam conhecer mais sobre biotecnologia e ter acesso a fontes seguras de informação. Estudos com consumidores japoneses mostraram que, os participantes que leram sobre biotecnologia foram mais acessíveis e forneceram mais respostas positivas às questões propostas no trabalho. Tal estudo contemplou perguntas sobre atitudes e interesse em relação à ciência e tecnologia de maneira geral, assim como em relação à biotecnologia e aceitação dos produtos específicos obtidos por estas tecnologias.

A reação dos consumidores em relação às novas tecnologias para a produção de alimentos está intimamente relacionada à credibilidade e confiança nas fontes de informação sobre os aspectos de seguridade do 
produto final (FREWER et al., 1995; FREWER et al., 1996a). Segundo HOBAN (1996b) a credibilidade na informação permite ao consumidor admitir os benefícios da nova tecnologia em termos de saúde pública e da qualidade ambiental.

Os estudos de aceitação do consumidor podem desempenhar importante papel neste contexto, e o contato direto com informação de familiares, amigos e representantes do público, de maneira geral, é também importante fator no complexo processo social de aceitação de novas tecnologias (HAMSTRA et al., 1996).

Houve mudança na própria concepção da indústria, que procura descobrir o que o consumidor quer comprar para depois oferecer produtos com aqueles atributos (CATHRO, 1992; ZAICHKOWSKY, 1991). Foi percebida a necessidade de verificar anteriormente a demanda do mercado, visto ser mais fácil atender aos anseios do consumidor e oferecer produto que supra estas expectativas, do que depois do produto pronto, criar campanhas que o convença a comprar aquele produto novo já inserido no mercado (DELIZA et al., 1999).

A preocupação do consumidor em relação às novas tecnologias e seus possíveis riscos pode gerar resistência ao uso da irradiação, da biotecnologia e de outras tecnologias que são decorrentes do progresso técnico-científico (McNUTT, 1988). Segundo CARDELLO (1997) para a aceitação de produtos, obtidos por tecnologias não-convencionais, torna-se necessário investimento em programas de educação/informação ao consumidor, para reduzir "os medos" dos consumidores sobre estes produtos.

A embalagem/rótulo dos alimentos desempenham importante papel na seleção dos mesmos, pois é a maior fonte de informação para os consumidores (FOOD..., 1989). Os vários aspectos da embalagem (marca comercial, preço, ilustração, informação, cor, entre outros) são responsáveis pela formação da expectativa, a qual pode contribuir para a rejeição do produto antes mesmo deste ser ingerido. Dentre tais aspectos, a informação é considerada bastante relevante (DELIZA, 1996). Assim, informar no rótulo a tecnologia utilizada pode assumir grande impacto na decisão do consumidor.

\subsection{PERCEPÇÃO DE QUALIDADE}

Muitas empresas já reconhecem a importância do consumidor no crescimento e desenvolvimento de seus negócios, e conseqüentemente estão destinando mais recursos para pesquisas de consumidor e de mercado. Existe considerável impulso para se compreender melhor o seu comportamento, para desenvolver medidas rápidas e confiáveis para as 
respostas do consumidor relacionadas aos seus produtos e os do concorrente, e especialmente para entender o que estes consumidores querem dizer com a palavra "qualidade" (STONE et al., 1991). Qualidade pode ter significado amplo, sendo portanto difícil defini-la em padrão rígido, sem considerar as influências individuais e as de contexto. De maneira bem simples, "qualidade" pode significar a base da aceitação pelo consumidor. Além desta simples aceitação podem existir outras expectativas sobre o alimento, como valor nutricional, estabilidade na estocagem (MOSKOWITZ, 1995), as quais também afetam a percepção da qualidade.

Os requisitos básicos de qualidade podem ser resumidos em seguridade, disponibilidade, valor nutricional e frescor, mas devem incluir também as necessidades do consumidor com relação à variedade e conveniência, atingindo as expectativas relacionadas a preço/qualidade e propaganda (McNUTT, 1988). Alta qualidade significa satisfazer as necessidades e desejos do consumidor e não somente protegê-lo de problemas futuros. Qualidade alimentar é, assim, conceito relativo, baseado nas impressões do consumidor habitual de determinado alimento, e bastante relacionado com o conceito de aceitação. Por muitos anos esta visão foi ignorada, e no seu lugar desenvolveu-se sistema para avaliar a qualidade dos alimentos baseado apenas nos julgamentos de especialistas. Entretanto, a essência da qualidade do alimento deve ser baseada na aceitabilidade do produto pelo consumidor e não somente pela avaliação de provadores especializados (CARDELLO, 1995a). Admitindo que "qualidade alimentar" é "a aceitação de características perceptíveis (englobando noção de segurança, conveniência, custo, valor nutricional, além de características sensoriais) pelos consumidores habituais e pelo público alvo de determinado produto e suas categorias", esta definição engloba três aspectos. O uso do consumidor como referência focaliza a aceitação como a forma chave de medição e considera a relatividade do julgamento baseado em noções de qualificação de "categoria do produto" e "mercado alvo". A medição de qualidade passa do ambiente físico para o psicológico, porque para entender a qualidade dos alimentos é preciso compreender a psicologia da aceitação, da escolha e do consumo (CARDELLO, 1995a).

A aceitabilidade do produto pode ser definida por fatores intrínsecos e extrínsecos. Os fatores intrínsecos compreendem a aparência do alimento, aroma, sabor e textura, e os fatores extrínsecos são externos ao alimento e inclui o contexto cognitivo, social, étnico, cultural, além de variáveis de atitude. A análise sensorial muitas vezes considerou apenas as variáveis intrínsecas afetando a aceitação do alimento (CARDELLO, 1993). Entretanto, a tendência mais recente enfoca abordagem mais ampla, considerando também os fatores extrínsecos (CARDELLO, 1995b).

A percepção de qualidade torna-se bastante relevante, devido à necessidade de existir coerência entre os conceitos do consumidor e da 
indústria, de maneira que o consumidor lucre com produtos seguros e com qualidade, vistos sob todos os ângulos.

\subsection{DIFERENÇAS INDIVIDUAIS DOS CONSUMIDORES INTERFERINDO NA PERCEPÇÃO DO PRODUTO}

Nem todos os indivíduos reagem da mesma maneira para diferentes produtos e tecnologias e se fosse possível identificar os fatores, conscientes e inconscientes, que operam no momento da compra, poderia ser possível prever a escolha final do consumidor. Tradicionalmente, a tentativa de compreender a escolha do alimento pelo consumidor tem sido esforço multidisciplinar de psicólogos, cientistas sensoriais, antropólogos, nutricionistas, fisiologistas e pesquisadores de marketing (CARDELLO, 1995c). Segundo WESTPHAL (1997) o entendimento do comportamento do consumidor frente à aquisição de alimentos pelos profissionais de marketing constitui-se em ponto crítico, visto que a compra de produtos alimentícios é direcionada mais pela emoção humana do que pela sua necessidade fisiológica. Tem sido evidenciado que existem diferenças individuais na percepção da qualidade intrínseca do alimento (aparência, aroma, sabor e textura), e existem também variações individuais na maneira de utilização das informações externas ao alimento (preço, marca, propaganda, rotulagem, embalagem). Tais diferenças interagem de modo determinante no momento da escolha do produto no ponto de venda.

Muitos fatores podem ser responsáveis pela diferente percepção dos indivíduos, mesmo quando submetidos a estímulos idênticos. De acordo com o Modelo de Elaboração de Probabilidade ("Elaboration Likelihood Model" - ELM) existem duas rotas de persuasão: aquela que ocorre por meio de avaliação cuidadosa e racional dos argumentos (rota central) e a outra que é baseada em simples sugestão, afetiva ou comportamental, sem recursos para processamento cognitivo complexo (rota periférica) (PETTY \& CACIOPPO, 1986). Utilizando a rota central, o consumidor usa informação relevante para avaliar o produto e, quando utiliza a rota periférica, usa apenas simples sugestões ou influências do contexto, sem considerar os atributos reais do produto. Muitas variáveis podem moderar a escolha da rota cognitiva, e entre elas estão o «Need for Cognition» (NFC), humor, cansaço, nível de envolvimento na compra. O NFC representa a tendência do indivíduo em se engajar e gostar de pensar.

PETTY \& CACIOPPO (1986) sugeriram que, dependendo da tendência de cada indivíduo para gostar de pensar, haverá maior ou menor facilidade de persuadi-lo com as informações expostas em rótulos/embalagens/ propagandas. O NFC é variável utilizada para explicar a mudança de atitude depois do processamento da informação. Segundo HAUGTVEDT et al. (1992) o NFC parece ser a variável primária de diferença individual, influenciando a "motivação de pensar" e resultando na avaliação do 
anúncio, das mensagens de comunicação veiculadas e conseqüentemente na escolha e consumo do produto. Alguns indivíduos apresentam alto NFC, ou seja "gostam de pensar", e outros baixo NFC, ou seja, tendem a evitar o trabalho cognitivo. Indivíduos com alto NFC tendem a processar argumentos contidos nas propagandas mais extensivamente do que indivíduos com baixo NFC.

Pode-se considerar que as mudanças de atitude são tomadas por uma das duas rotas distintas de persuasão: a rota central ou a rota periférica. As mudanças de atitude via rota central são mais duradouras e podem ser preditivas do comportamento, enquanto que as mudanças de atitude via rota periférica são mais temporárias e não preditivas do comportamento (PETTY et al., 1983). Segundo INMAN et al. (1990) os indivíduos com alto NFC tendem a tomar decisões via rota central, e aqueles com baixo NFC utilizam a rota periférica.

O grau de envolvimento do indivíduo para a escolha do alimento pode contribuir para a tomada de decisão. Dependendo do tipo de produto, o consumidor estará mais ou menos envolvido na compra. Sob altas condições de envolvimento as pessoas tendem a exercer maior esforço cognitivo para avaliar os argumentos apresentados e sua atitude é resultado desta atividade de processar as informações (rota central). Sob baixas condições de envolvimento, a atitude parece ser afetada por simples sugestão de aceitação e rejeição no contexto de persuasão, sendo menos afetadas por argumentos de qualidade (rota periférica) (PETTY et al., 1983).

No momento da compra, o consumidor utiliza primeiramente a sua memória como fonte de informação para determinar sua escolha, procura informações suplementares de fontes externas (propagandas, embalagem, o preço, a marca, etc.) e processa todas as informações coletadas pela atividade cognitiva e depois armazena os resultados desta compra na memória para próxima compra (CHERNATONY, 1991). Entre uma compra e outra, vários fatores de comportamento e características de personalidade estão envolvidos na escolha de determinado produto em detrimento de outros. INMAN et al. (1990) demostraram que colocando apenas o aviso de promoção sem alterar o preço, as vendas do produto dobraram. O estudo revelou que o grupo de indivíduos com baixo NFC reagiu a ambas condições de promoção (com ou sem a redução do preço do produto em promoção), enquanto que o grupo de indivíduos com alto NFC reagiu somente à promoção real. Para os consumidores com baixo NFC, apenas o aviso de promoção representou mudança suficientemente significativa no comportamento, induzindo a escolha da marca em promoção. Para os indivíduos com alto NFC foi necessário preço realmente reduzido. Estudos feitos com rótulos para verificar a influência que estes exerceram na percepção das características sensoriais do produto pelo consumidor revelaram que, indivíduos com alto NFC foram 
mais difíceis de serem persuadidos, mantendo as avaliações antes e depois de observarem os rótulos dos alimentos (DELIZA, 1996).

A consciência em relação à própria saúde também é uma característica individual relevante na escolha de produtos alimentícios (DAVIES et al., 1995). Estudos recentes mostraram que indivíduos com maior consciência em relação à saúde foram mais predispostos ao consumo de alimentos orgânicos (SCHIFFERSTEIN \& OUDE OPHUIS, 1998). Foi observada correlação entre a consciência do indivíduo em relação à sua própria saúde e a preocupação com o meio ambiente, refletindo a escolha de determinados produtos em detrimento de outros. Deste modo, as tecnologias não convencionais, que apresentam apelos relacionados às questões ambientais, podem ter maior aceitabilidade entre os consumidores mais preocupados com a própria saúde.

\section{CONCLUSÃO}

As características de personalidade exercem influência significativa nas respostas do consumidor para produtos novos e/ou aqueles obtidos por novas tecnologias, e apesar disso, os estudos nesta área são ainda incipientes. A literatura é escassa sendo necessário maior interligação entre a pesquisa e o marketing tentando atingir este objetivo comum.

Para o desenvolvimento de estratégias de marketing torna-se necessário o conhecimento do mercado e dos motivos que levam determinados consumidores a comprarem certos produtos. Assim, conhecer as características individuais é fundamental para a introdução de produtos novos no atual mercado competitivo.

O melhor entendimento do comportamento do consumidor frente aos estímulos expostos favorecerá 0 atendimento de suas expectativas, trazendo satisfação e, conseqüentemente, aumento no lucro das empresas.

\section{Abstract}

This article presents a literature review on non-conventional technologies applied to food production, and emphasises the consumer's individual differences which differently affect the food perception.

\section{REFERÊNCIAS BIBLIOGRÁFICAS}

1 GENETIC engineering is fast moving from research labs onto grocery shelves. But along the way, it's making a detour onto the front pages. Food Processing, v. 58, n. 5, p. 25-35, 1997. 
AHSON, K. What is actually happening in agri-food biotechnology? Nutrition and Food Science, v. 1, p. 26-31, January/February 1997.

ARROYO, G., PRESTAMO, G. Respuesta de los microorganismos contaminantes de productos vegetales a la accion de las altas presiones. Alimentaria, v. 273, p. 103-108, Junio 1996.

BHAT, A., JOSHI, V.K. Ohmic processing of foods, the concept, application, present status and future outlook. Alimentaria, p. 83-88, Jan./Feb. 1998.

BOLIN, H.R., HUXSOLL, C.C. Storage stability of minimally processed fruit. Journal of Food Processing and Preservation, n. 13, p. 281-292, 1989.

BULFIELD, G. Genetic modification of farm animals. British Food Journal, v. 98, n. 4/5, p. 10-13, 1996.

CAL-VIDAL, J. Effects of combination of solutes on depression of water activity. Ciência e Tecnologia de Alimentos, Campinas, v. 1, n. 2, p. 73-84, 1981.

CANTWELL, M. Food safety: microbiological concerns. Perishable Handling Newsletter Issue, v. 81, p. 15-16, 1995.

CARDELLO, A. V. What do consumers expect from low-cal, low-fat, lite foods? Cereal Foods World, v. 38, n. 2, p. 96-99, 1993.

CARDELLO, A. V. Food quality: relativity, context and consumer expectations. Food Quality and Preference, v. 6, p. 163-170, 1995a.

CARDELLO, A.V. Sensory evaluation and food packaging. Cereal Foods World, v. 40, n. 7, p. 502-504, 1995b.

CARDELLO, A. V. Sensory evaluation and consumer food choice. Cereal Foods World, v. 40, n. 11, p. 876-878, 1995c.

CARDELLO, A. V. Food stereotypes: prejudice in the pantry. Cereal Food World, v. 42, n. 4, p. 231-233, 1997.

CASTRO, A. J., BARBOSA-CÁNOVAS, V., SWANSON, B. G. Microbial inactivation of foods by pulsed electric fields. Journal of Food Processing and Preservation, v.17, p. 47-73, 1993.

CATHRO, J. Trends in the consumer perception of foods. Food Tech. Int. Europe, p. 29-32, 1992. preferences: a two-country study. Journal of International Consumer Marketing, v. 9, n. 1, p. 43-55, 1996. 
CHEFTEL, C. J. Review: high-pressure, microbial inativation and food preservation. Food Science and Technology International, v. 1, p. 75-90, 1995.

CHERNATONY, L. Facilitating consumer choice decisions: the importance of branding cues. British Food Journal, v. 93, n. 9, p. 50-56, 1991.

CHIRIFE J., FAVETTO, G.J. Some physic-chemical basis of food preservation by combined methods. Food Research International, v. 25, p. 389-396, 1992.

21 CHRISTIE,G.B.Y., MACDIARMID, J.I., SCHLIEPHAKE, K., TOMKINS, R.B. Determination of film requirements and respiratory behaviour of fresh produce in modified atmosphere packaging. Postharvest Biology and Technology, v. 6, p. 41-54, 1995.

DAVIES, A., TITTERINGTON, A.J., COCHRANE, C. Who buys organic food? A profile of the purchasers of organic food in Northern Ireland. British Food Journal, v. 97, n. 10, p. 17-23, 1995.

DELIZA, R. The effects of expectation on sensory perception and acceptance. Reading, UK, 1996. 198 p. PhD Thesis, University of Reading, Food Science Department.

24 DELIZA, R., ROSENTHAL, A., HEDDERLEY, D., MacFIE, H.J.H., FREWER, L.J. The importance of brand, product information and manufacturing process in the development of novel environmentally friendly vegetable oils. J. Int. Food Agribusiness Marketing, v. 10, n. 3, p. 67-77, 1999.

DUNN, J. Pulsed light and pulsed electric field for foods and eggs. Poultry Science, v. 75, p. 1133-1136, 1996.

EARNSHAW, R. High pressure food processing. Nutrition \& Food Science, n. 2, p. 8-11, March/April 1996.

ELLAHI, B. Genetic engineering for food production - What is it all about? British Food Journal, v. 96, n. 8, p. 13-23, 1994.

ERICKSON, L.E. Recent developments in intermediate moisture foods. Journal of Food Protection, v. 45, n. 5, p. 484-491, 1982.

29 FAO/OMS. Codex Alimentarius. Roma, 1995. v. 1 A.

FEEHAN, T. Biotechnology: the communication challenge is on. International Food Ingredients, v. 1, p. 14-18, 1997.

31 FREWER, L. J., HOWARD, C., SHEPHERD, R. Genetic engineering and food: what determines consumer acceptance? British Food Journal, v. 97, n. 8, p. 31-36, 1995. 
FREWER, L. J., HOWARD, C., SHEPHERD, R. Effective communication about genetic engineering. British Food Journal, v. 98, n. 4-5, p. 4852, 1996a.

FREWER, L. J., HOWARD, C., SHEPHERD, R. The influence of realistic product exposure on attitudes towards genetic engineering of food. Food Quality and Preference, v. 7, n. 1, p. 61-67, 1996b.

FREWER, L. J., MOLES, A., SABA, A. Public concerns about general and specific applications of genetic engineering: a comparative study between the UK and Italy. Nutrition \& Food Science, v. 1, p. 19-29, 1998.

HAMSTRA, A. M., SMINK, C. Consumers and biotechnology in the Netherlands. British Food Journal, v. 98, n. 4-5, p. 34-38, 1996.

HASHIM, I.B., RESURRECCION, A.V. A., McWATTERS, K.H. Consumer attitudes toward irradiated poultry. Food Technology, v. 50, n. 3, p. 7780, 1996.

HAUGTVEDT, C. P., PETTY, R.E., CACIOPPO, J.T. Need for cognition and advertising: understanding the role of personality variables in consumer behavior. Journal of Consumer Psychology, v. 1, n. 3, p. 239-260, 1992.

HENSON, S. Demand-side constraints on the introduction of new food technologies: the case of food irradiation. Food Policy, v. 20, n. 2, p. 111-127, 1995.

HOBAN, T. J. Anticipating public reaction to the use of genetic engineering in infant nutrition. Am. J. Clin. Nutr., v. 63, n. 4, p. 657-662, 1996a.

HOBAN, T. J. How Japanese consumers view biotechnology. Food Technology, v. 50, n. 7, p. 85-88, 1996b.

41 HOBAN, T. J. Trends in consumer acceptance and awareness of biotechnology. Journal of Food Distribution Research, v. 27, n. 1, p. 1-10, 1996c.

HOOVER, D. G., METRICK, C., PAPINEAU, A. M., FARKAS, D.F., KNORR, D. Biological effects of high hydrostatic pressure on food microorganisms. Food Technology, v. 43, n. 3, p. 99-107, March 1989.

HOOVER, D.G. Minimally processed fruits and vegetables: reducing microbial load by nonthermal physical treatments. Food Technology, v. 51, n. 6, p. 66-69, June 1997.

INMAN, J. J., McALISTER, L., HOYER,W.D. Promotion signal: proxy for a price cut? Journal of Consumer Research, v. 17, p. 74-81, 1990. 
JARDIM, D.C.P. Uso de métodos combinados para a produção de alimentos. In: AGUIRRE, J.M., GASPARINO FILHO, J. Desidratação de frutas e hortaliças. Campinas, 1996. p. 71-76 (Manual técnico do ITAL).

JONES, L. Food biotechnology: current developments and the need for awareness. Nutrition and Food Science, v. 6, p. 5-11, 1996.

KIM, H.J., CHOI, Y.M., YANG, T.C.S., TAUB, I.A., TEMPEST, P., SKUDDER, P., TUCKER, G., PARROT, D.L. Validation of ohmic heating for quality enhancement of food products. Food Technology, v. 50, n. 5, p. 253-261, 1996.

KLEIN, B.P. Nutritional consequences of minimal processing of fruits and vegetables. Journal of Food Quality, v. 10, p. 179-193, 1987.

KNORR, D. Effects of high-hydrostatic - pressure, processes on food safety and quality. Food Technology, v. 47, n. 6, p. 156-161, June 1993.

LARKIN, J. W., SPINAK, S. H. Safety considerations for ohmically heated, aseptically processed, multiphase low-acid food products. Food Technology, v. 50, n. 5, p. 242-245, May 1996.

LEISTNER, L., GORRIS, L.G.M. Food preservation by hurdle technology. Trends in Food Science \& Technology, v. 6, p. 41-46, 1995.

LEISTNER, L. Food preservation by combined methods. Food Research International, v. 25, p. 151-158, 1992.

53 MARQUEZ, V.O., MITTAL, G.S., GRIFFITHS, M.W. Destruction and inhibition of bacterial spores by high voltage pulsed electric field. Journal of Food Science, v. 62, n. 2, p. 399-401, 1997.

McLLVEEN, H. Product development and the consumer: the reality of managing creativity. Nutrition \& Food Science, v. 6, p. 26-30, 1994.

McNUTT, K. Consumer attitudes and the control function. Food Technology, v. 42, n. 12, p. 97-108, 1988.

MERTENS, B. Under pressure. Food Manufacture, v. 67, n. 11, p. 23-24, November 1992.

57 MITTAL, G.S. Food biotechnology: techniques and applications. Canada : Technomic Publishing, 1992.

58 MOSKOWITZ, H. R. Food quality: conceptual and sensory aspects. Food Quality and Preference, v. 6, p. 157-162, 1995.

59 PARROT, D.L. Use of ohmic heating for aseptic processing of food particulate. Food Technology, v. 46, n. 12, p. 68-72, 1992. 
PEACOCK, W.J. Genetic engineering of crop plants will enhance the quality and diversity of foods. Food Australia, v. 46, n. 8, p. 379-381, 1994.

61 PETTY, R. E., CACIOPPO, J.T., SCHUMANN, D. Central and peripheral routes to advertising effectiveness: the moderating role of involvement. Journal of Consumer Research, v. 10, p. 135-146, 1983.

PETTY, R.E., CACIOPPO, J.T. Communication and persuasion : central and peripheral routes to attitude change. New York, NY : SpringerVerlag, 1986.

63 PHILLIPS, C.A. Review: modified atmosphere packaging and its effects on the microbiological quality and safety of produce. International Journal of Food Science and Technology, v. 31, p. 463-479, 1996.

POHLMAN, A. J., WOOD, O.B., MASON, A.C. Influence of audiovisuals and food samples on consumer acceptance of food irradiation. Food Technology, v. 48, n. 12, p. 46-49, 1994.

PSZCZOLA, D.E. Twenty ways to market the concept of food irradiation. Food Technology, v. 51, n. 2, p. 46-48, 1997.

QIN, B.L., POTHAKAMURY, U.R., VEGA-MERCADO, H., MARTÍN, O., BARBOSA-CÁNOVAS, G.V., SWANSON, B.G. Food pasteurisation using high-intensity pulsed electric fields. Food Technology, v. 49, n. 12, p. 55-60, 1995.

67 REYES, V.G. Improved preservation systems for minimally processed vegetables. Food Australia, v. 48, n. 2, p. 87-90, 1996.

ROSENTHAL, A., SILVA, J. L. Alimentos sob pressão. Engenharia de Alimentos, v. 14, p. 37-39, 1997.

ROSENTHAL, A., MACKEY, B., BIRD, A. Fruit juices preservation by ultra high pressure technology. In: WORLD CONGRESS OF FOOD SCIENCE AND TECHNOLOGY, 10., Sydney, Australia, Out. 1999. Proceedings... Sydney, Australia, 1999.

70 ROTH, V. J. Comparison of Ontario consumers and farmers attitudes regarding selected environment issues. Proceedings, v. 11, n. 3, p. 330-338, 1990.

71 RUSSELL, E. The engineering in genetic modification. Food Manufacture, v. 73, n. 3, p. $36-38,1998$.

SANGRONIS, E., POTHAKAMURY, U., RAMOS, A.M., IBARZ, A., BARBOSA-CÁNOVAS, G.V., SWANSON, B.G. La alta presion hidrostática: una alternativa en el procesamiento no termico de alimentos. Alimentaria, n. 283, p. 33-43, Junho 1997. 
SCHER, M. Biotechnology's evolution spurs food revolution - Foods from new biotechnology coming to market. Food Processing, v. 54, n. 1, 1993.

SCHIFFERSTEIN, H. N. J., OUDE OPHIUS, P. A. M. Health-related determinants of organic food consumption in the Netherlands. Food Quality and Preference, v. 9, n. 3, p. 119-133, 1998.

SCHOlTEN, A.H., FEENSTRA, M.H., HAMSTRA, A.M. Public acceptance of foods from biotechnology. Food Biotechnology, v. 5, n. 3, p. 331345, 1991.

SCHUTZ, H. G., CARDELLO, A.V. Information effects on acceptance of irradiated foods in a military population. Dairy Food and Environmental Sanitation, v. 17, n. 8, p. 470-481, 1997.

SENDRA, E., CAPELLAS, M., GUAMIS, B., FELIPE, X., MOR-MUR, M., PLA, R. Revisión : irradiación de alimentos - aspectos generales. Food Science and Technology International, v. 2, p. 1-11, 1996.

SEYDERHELM, I., BOGUSLAWSKI, S., MICHAELIS, G., KNORR, D. Pressure induced inactivation of selected food enzymes. Journal of Food Science, v. 61, n. 2, p. 308-310, 1996.

SHEWRY, P.R., LAZZERI, P. Genetic manipulation of crops. British Food Journal, v. 98, n. 4/5, p. 5-9, 1996.

SKUDDER, P.J. Ohmic heating in food processing. Asian Food J., v. 4, n. 4, p. 10-11, 1989.

TAOUKIS, P.S., BREENE, W.M., LABUZA, T.P. Intermediate moisture foods. Advanced in Cereal Science and Technology, St. Paul, 9, p. 91-128, 1988.

THAKUR, B.R., SINGH, R.K. Food irradiation: chemistry and applications. Food Reviews International, v. 10, n. 4, p. 437-473, 1994.

TORREZAN, R., JARDINE, J.G., VITALI, A.A. Preservação de alimentos com o uso dos métodos combinados : uma revisão. B. SBCTA, v. 31, n. 2, p. 214-228, jul/dez. 1997.

TUCKER, G. Biotechnology and enzymes in the food industry. British Food Journal, v. 98, n. 4/5, p.14-19, 1996.

VEGA-MERCADO, H., MARTÍN-BELLOSO, O., QIN, B.L., CHANG, F.J., GÓNGORA-NIETO, M.M., BARBOSA-CÁNOVAS, G.V., SWANSON, B.G. Non-thermal food preservation: pulsed electric fields. Trends in Food Science \& Technology, v. 8, p. 151-156, 1997. 
VERRALL, M. Lay panel backs gene-modified plants but urges stricter monitoring. Nature, v. 372, n. 10, p. 122, 1994.

WANDEL, M., BUGGE, A. Environmental concern in consumer evaluation of food quality. Food Quality and Preference, v. 8, n. 1, p. 19-26, 1997.

WATTS, T. A., LIEFELD, J.P., ROTH, V.J. Consumer attitudes regarding environmental issues. Proceedings, v. 11, n. 3, p. 401-409, 1990.

WESTPHAL, L. Food promotion - catching the consumer's attention. Direct Marketing, v. 59, n. 10, p. 18-20, 1997.

91 WILLIAMS, A. New technologies in food preservation and processing: part 1. Nutrition and Food Science, v. 6, p. 16-19, November/December 1993.

YEE, L. L. Effect of collective orientation and ecological attitude environmental commitment: the moderating role of consumer demographics and product involvement. Journal of International Consumer Marketing, v. 9, n. 4, p. 31-53, 1997.

ZAICHKOWSKY, J. L. Consumer behaviour: yesterday, today and tomorrow. Business Horizons, p. 51-58, May/June 1991.

ZHANG, Q., QIN, B.L., BARBOSA-CÁNOVAS, G.V., SWANSON, B.G. Inactivation of $E$. coli for food pasteurisation by high-strength pulsed electric fields. Journal of Food Processing and Preservation, v. 19, p. 103-118, 1995.

ZOLTAI, P., SWEARINGEN, P. Product development considerations for ohmic processing. Food Technology, v. 50, n. 5, p. 263-266, 1996.

ZIMMERNAN, L., KENDALL, P., STONE, M., HOBAN, T. Consumer knowledge and concern about biotechnology and food safety. Food Technology, v. 48, n. 11, p. 71-77, 1994. 